\title{
Assessment and Management of Acute Volar Rim Fractures
}

\author{
John J. Heifner, MD ${ }^{1}$ Jorge L. Orbay, $\mathrm{MD}^{2}$ \\ ${ }^{1}$ St. George's University School of Medicine, Great River, New York, \\ New York \\ ${ }^{2}$ The Miami Hand and Upper Extremity Institute, Miami, Florida
}

Address for correspondence Jorge L. Orbay, MD, 8905 SW 87 Avenue, Miami, FL 33176 (e-mail: jlorbay@gmail.com).

J Wrist Surg 2022;11:214-218.

\begin{abstract}
\section{Keywords}

- distal radius fracture

- fragment specific fixation

- volar marginal fragments

- volar rim

- watershed line

The volar rim of the distal radius is the only bony restraint to volar carpal subluxation. Higher loads across the volar rim require stable and rigid fixation to maintain reduction and allow healing while rehabilitation begins. Volar marginal fragments are not amenable to buttressing by fixed angle volar locking plates. Appropriate management of volar marginal fragments comprises two steps-recognition of their presence and rigid anatomical repair. The best opportunity for success in the presence of a volar marginal fragment is its adequate initial treatment. The purpose of this review is to reinforce the importance of a complete preoperative and intraoperative evaluation of distal radius fractures. Volar marginal fragments can easily be overlooked even following initial reduction and fixation. Understanding the relevant anatomy and loading parameters can facilitate intraoperative decisions on approach and fixation, which are integral to achieving optimal clinical outcomes.
\end{abstract}

Patterns in distal radius fractures can vary due to bone quality, mechanics of injury, and magnitude of the impact to the extremity. ${ }^{1-3}$ Comminution and displacement are often linearly related to energy applied, resulting in predictable patterns. ${ }^{2}$ Fractures involving the articular surface often divide the lunate from the scaphoid fossa and the lunate fossa into anteromedial and posteromedial fragments. Fixation of the volar ulnar (anteromedial) fragment can be problematic with smaller and distal fragments not amendable to buttressing with volar locking plates. Additionally, these fragments may be avascular, resulting in poor healing. These small anteromedial fragments are referred to as the volar marginal fragments (VMF); while rare, their recognition and fixation are essential for clinical success.

received

March 22, 2021

accepted

April 6, 2021

published online

July 30,2021

\section{Bony Morphology}

The volar rim of the distal radius is the only part of the articular surface that provides support against volar carpal translation. $^{4-7}$ These fragments are inherently unstable, because they are offset palmarly from the radial shaft (-Fig. 1). At the same time, they carry a large portion of the load applied to the lunate fossa. Differing degrees of instability may develop if anatomical variation yields greater volar projection of this rim. $^{8}$ Variable anatomy can limit plate positioning, which may prevent the effectiveness of buttress fixation. Mekhail et al describes the transverse morphology of the distal radius as presenting a lazy $\mathrm{S}$ appearance with a distal convexity on its ulnar aspect. ${ }^{9}$

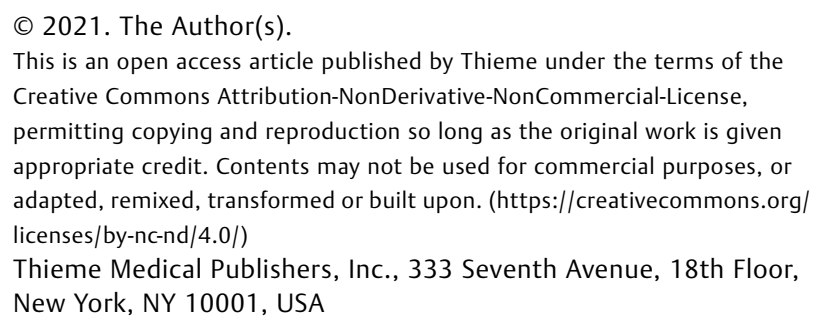

This is an open access article published by Thieme under the terms of the Creative Commons Attribution-NonDerivative-NonCommercial-License, permitting copying and reproduction so long as the original work is given appropriate credit. Contents may not be used for commercial purposes, or adapted, remixed, transformed or built upon. (https://creativecommons.org/ licenses/by-nc-nd/4.0/) Thieme Medical Publishers, Inc., 333 Seventh Avenue, 18th Floor, New York, NY 10001, USA 


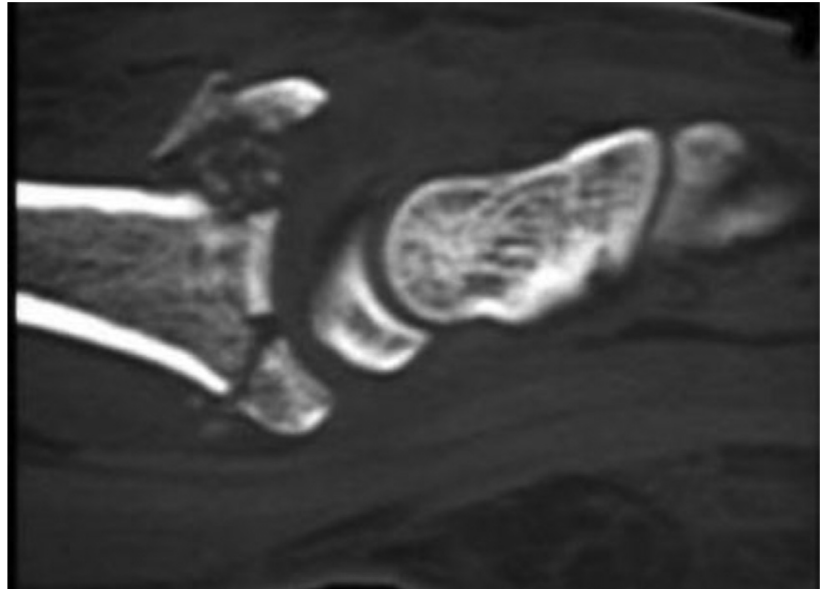

Fig. 1 Computed tomography showing volar rim fragment of intraarticular distal radius fracture.

The volar rim and wrist ligaments work together in maintaining carpal stability. The volar margin of the lunate facet is the site of origin of the short radiolunate and volar distal radioulnar ligaments. ${ }^{10}$ Microdissection analysis of the short radiolunate ligament demonstrates robust thickness, density of fibers, and an orientation that suggests an important role in kinematics as well as stability. ${ }^{11}$ For these reasons, distal radius fractures with a VMF have a high risk of subsequent volar carpal subluxation if not properly addressed.

The watershed line was originally described by Orbay in 2005 as a transverse ridge that limits the distal concave surface of the distal radius, with the intention of raising awareness of the proximity of the flexor tendons to volar

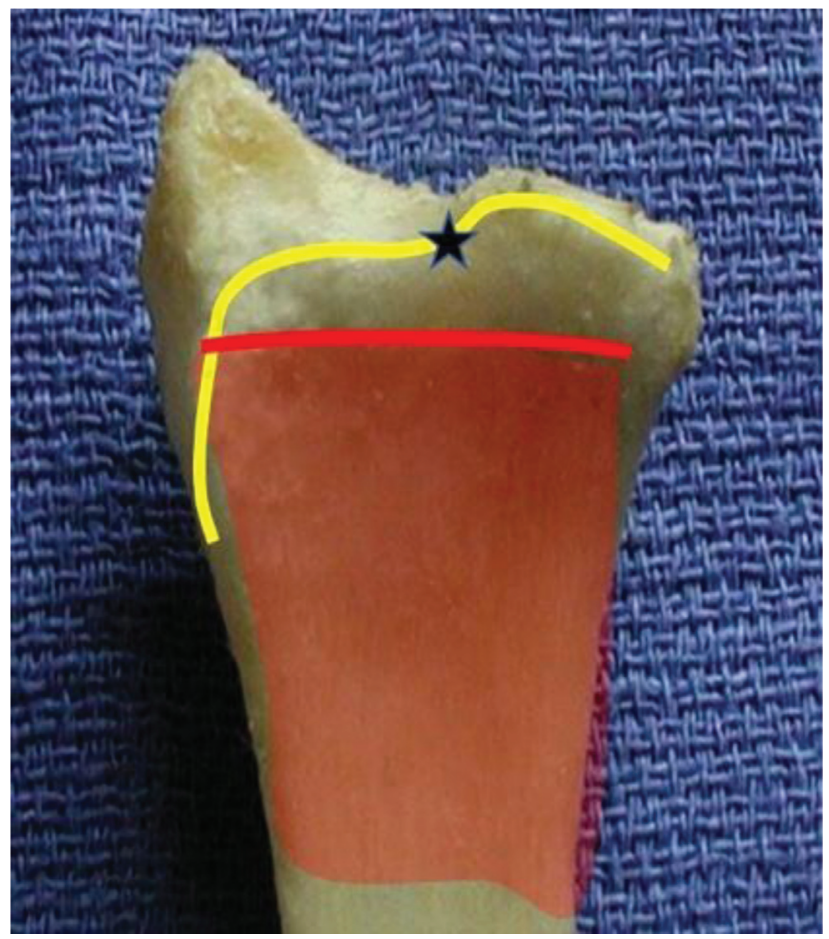

Fig. 2 The watershed line (yellow line) is the distal extent of the pronator fossa and is several millimeters distal to the pronator quadratus muscle (red shading).

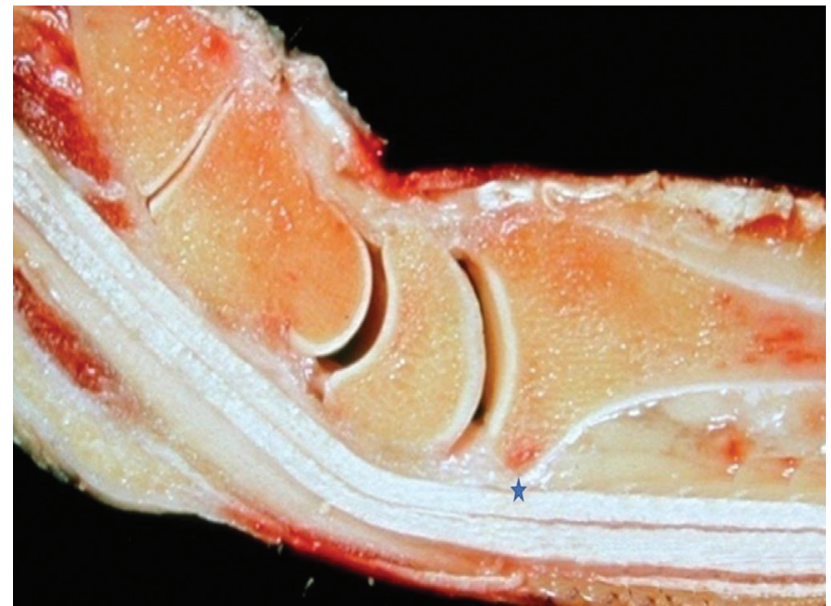

Fig. 3 Cadaveric cross-section showing the point at which the flexor tendons are closest to the volar radius (star) at the watershed line.

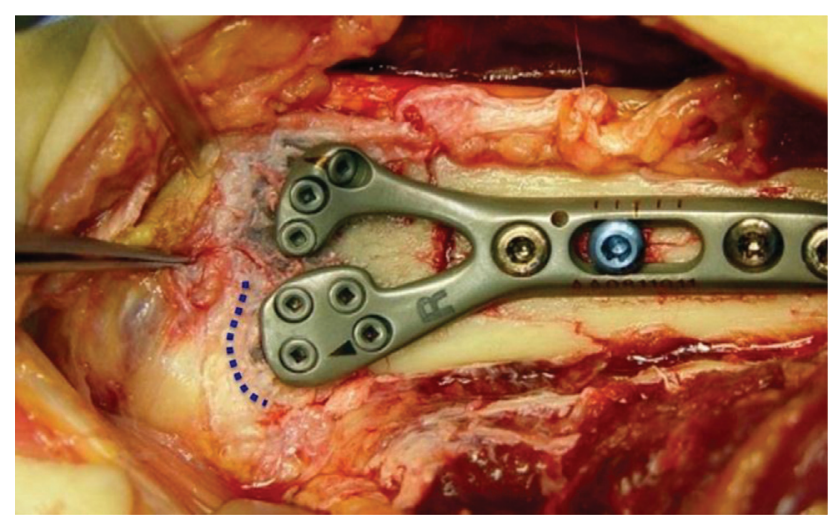

Fig. 4 Intraoperative photograph showing a volar locking plate placed 2 to $3 \mathrm{~mm}$ proximal to the watershed line (blue dotted line) to avoid flexor tendon impingement.

plates $^{12}$ (-Fig. 2). Varying interpretations of the watershed line have appeared in the literature, therefore we will briefly clarify. ${ }^{13}$ The watershed line is the most distal projection of the volar margin of the radius and is the feature that is closest to the flexor tendons (-Fig. 3). It is the distal limit of the pronator fossa concavity, with the radius sloping dorsally toward the joint line from this position. For this reason, it is used to determine the correct distal placement of a volar plate (-Fig. 4). Proper plate placement allows maximum buttressing support while minimizing the probability of tendon injury. Soong et al devised a grading system to classify volar plate placement. He described the critical line as a line tangential to the most volar aspect of the volar rim, parallel to the volar surface of the radial shaft. ${ }^{14}$ The critical line is an imaginary demarcation that is parallel to the volar surface of the radial shaft and used to classify the placement of a volar plate. Volar plates should not extend volar to this line. Therefore, the critical and the watershed lines are approximately perpendicular to each other, and they describe plate positions in different planes. Validity for Soong's classification has been reported with significantly higher Soong grades in patients who undergo volar plate removal compared with those with retained plates. ${ }^{15}$ 


\section{Joint Loading Mechanics}

Radiocarpal load distribution between the scaphoid and lunate fossa contributes to the importance of recognition and appropriate fixation of VMFs. With the wrist in extension and ulnar deviation, a common functional position, ${ }^{16}$ the lunate fossa can bear more load than the scaphoid fossa. ${ }^{17}$ Reports have quantified a wide spectrum of load distribution between the scaphoid and lunate fossa ${ }^{18-20}$, with a more equitable distribution noted, using a model intended to mimic in vivo force production. While agreement is lacking, the lunate fossa may bear a higher percentage of load than was originally thought, especially during activity. ${ }^{17}$ Further, loading asymmetry has been noted, with higher loads being measured on the volar aspect of the lunate fossa in certain joint positions. ${ }^{18,21}$ According to Wolf's law, regions of higher stress, due to increased loading, produce higher densities of subchondral bone. ${ }^{22}$ Giunta et al found higher densities volarly on the lunate fossa, which further confirms the higher loads that are generated across this region. ${ }^{23}$ These higher loads, which can be imparted onto the volar rim, require the fragment to have very stable and rigid fixation. This will ensure maintenance of reduction and allow healing, as early motion and rehabilitation begins.

\section{Fracture Characteristics}

VMF, by definition, are fragments which are not amenable to buttressing by fixed angle volar locking plates. ${ }^{24}$ Given that the watershed line is approximately $3 \mathrm{~mm}$ proximal from the joint line at the lunate fossa, and that volar plates should not be positioned closer than $2 \mathrm{~mm}$ to the watershed line to prevent projecting above the critical line (Soong grade 1), the length of the volar rim which remains unsupported by volar plates is at a minimum of $5 \mathrm{~mm}$. Fragments longer than $5 \mathrm{~mm}$ can still be problematic, as sufficient contact between the buttressing plate surface and the bone fragments must exist to provide stability. Volar ulnar fragments shorter than $15 \mathrm{~mm}$ have a high risk of becoming displaced. ${ }^{25}$ While commonly nondisplaced, these fragments are prone to failure if not adequately fixed (-Fig. 5). Thus, they have been described as the Achilles heel of distal radius fractures. ${ }^{24}$ The importance of this component of distal radius fractures was initiated by the work of Harness et al, who reported a small series of patients with initial postoperative reduction but subsequent loss of fixation of the lunate facet fragment. ${ }^{5}$ Identification of these fragments requires both a high index of suspicion and preoperative and intraoperative attention to detail. Preoperative imaging may not reveal the presence of a VMF, given their small size and the fact that they may not be displaced.

\section{Fracture Management}

Adequate exposure is important to ensure identification of these fragments. Distal release of the flexor carpi radialis (FCR) tendon sheath combined with elevation of all soft tissues proximal to the watershed line (extended flexor carpi radialis approach) allows the proper visualization of these fracture

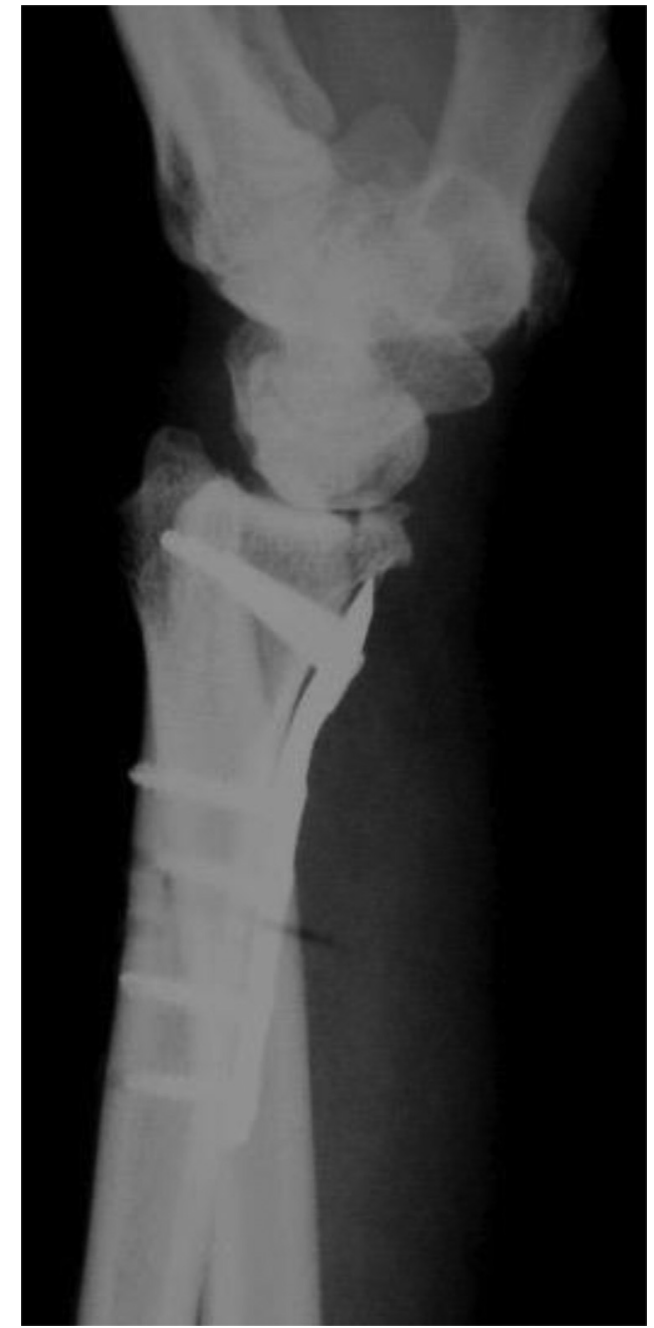

Fig. 5 Lateral radiograph of malreduced volar marginal fragment and volar carpal subluxation, following volar locking plate fixation with insufficient buttressing capacity.

lines. ${ }^{26}$ When addressed acutely with anatomic reduction and rigid fixation, distal radius fractures with VMFs have a high likelihood of success. ${ }^{5}$ When primary fixation has failed, this outcome probability decreases due to resorption of the bony fragment from micromotion and insufficient blood supply. ${ }^{24}$ Often VMFs have no vascular supply, being detached from their intraosseous irrigation and having no retrograde vessel on their distal capsular attachment. ${ }^{27,28}$ With decreasing fragment size, survival potential can diminish due to fixation difficulty; thus, the importance of acute treatment with rigid fixation to allow revascularization.

Internal fixation options for volar rim fragments include specifically designed plates, screws, hook plates, Kirschner wire configurations, and hook extensions to the volar plate.

Distal volar locking plates are designed to be placed distal to the watershed line, with the intention of increasing buttressing support. By definition, these plates cross the watershed line; therefore, they place the flexor tendons in direct contact with the implant. Favorable results have been reported with these devices, although authors discussed the potential complications due to attritional tendon rupture and the possibility of an additional procedure for plate removal. ${ }^{29,30}$ Components 
of the plate design intended to mitigate tendon irritation include nontraumatic screw head surface and tendon contact distributed over a large smooth area.

Independent hook plates and wire-forms provide fixation that is more rigid than Kirschner wires while being lower profile than volar locking plates. The smaller dimensions of these implants can facilitate accurate placement to capture a specific fragment, but these are insufficient by themselves, and must be used in conjunction with other implants. Reports have shown satisfactory outcomes, and while tendon irritation was reported with early versions of this plate, ${ }^{31}$ more recent reports with lower profile devices have shown these complications to be less prevalent. ${ }^{32}$

Chin and Jupiter first described a wire loop fixation technique for treatment of intra-articular fragmentation in distal radius fractures. ${ }^{33}$ Their technique involved passing the wire through the radial metaphysis and then through the joint capsule. This option can be useful for certain fracture patterns but does not provide rigid enough fixation for most VMFs, even when used in conjunction with volar plating (-Fig. 6). Recently, surgeons have utilized Kirschner wire fixation in addition to volar locking plates. Moore et al describes a technique of fixing the distal fragment to the proximal fragments with bent Kirschner wires; then, applying a volar plate on top of the exposed wire to capture the distal fragment. ${ }^{34}$ While this technique and those utilizing fragment specific fixation ${ }^{31,35}$ have provided favorable outcomes with low rates of complications, these methods have to be utilized prior to the application of a volar fixed angle plate. Often, VMFs are found to be unstable after the fracture has already been reduced and fixed with a volar fixed angle

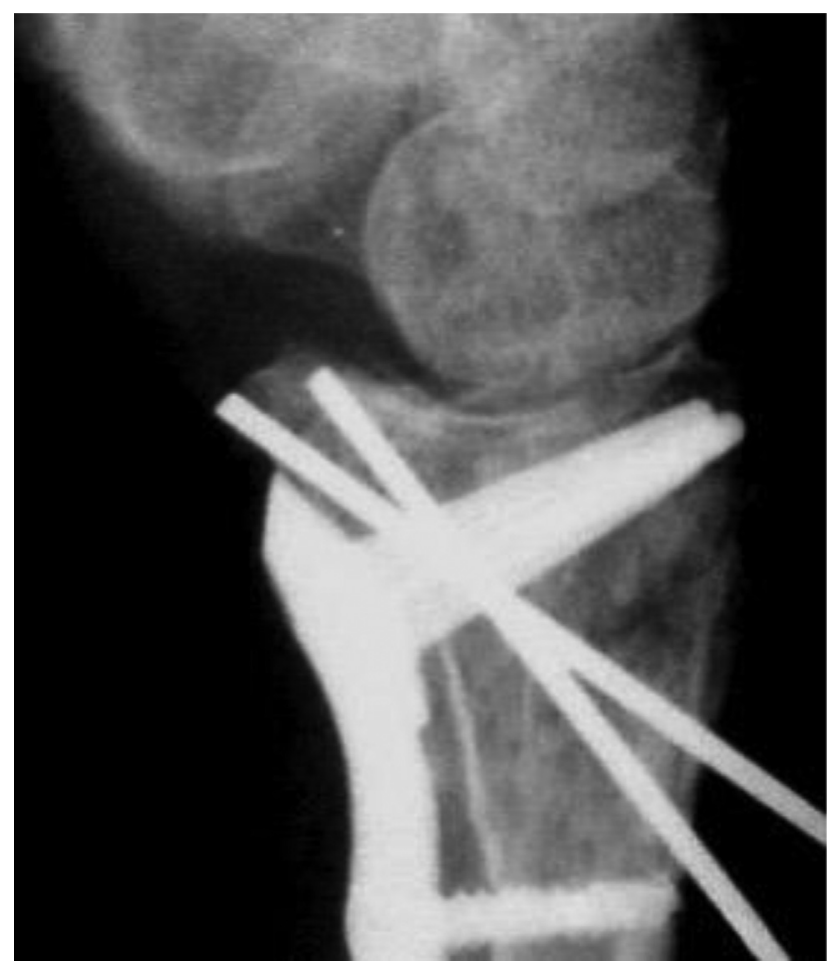

Fig. 6 Lateral radiograph showing volar marginal fragment being fixed with Kirschner wires to be removed after fracture healing.

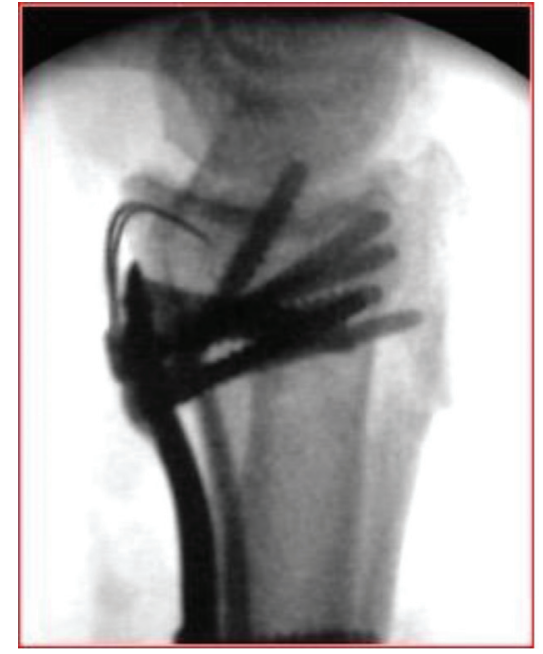

A

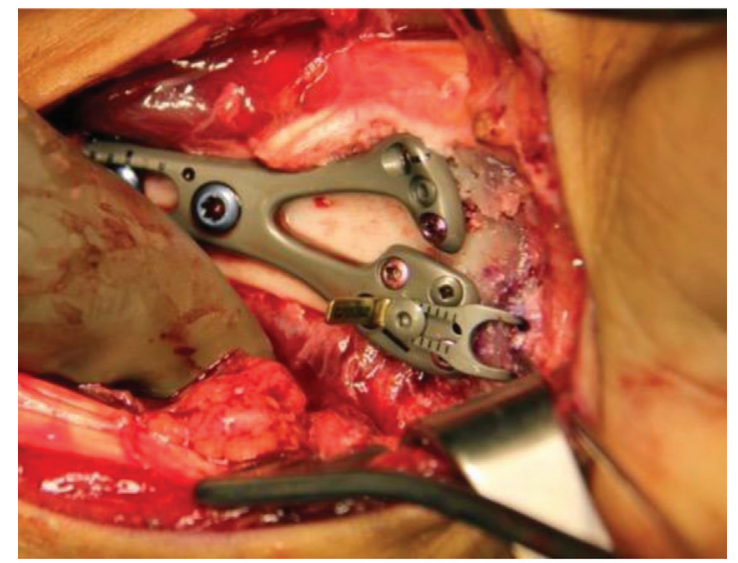

B

Fig. 7 Lateral fluoroscopy (A) and intraoperative photograph (B) of volar marginal fragment repaired with volar locking plate and hook plate extension.

plate. Therefore, the implants that are most useful are those which can be applied after the volar fixed angle plate.

Volar fixed angle plates, by themselves, can successfully neutralize all articular fragments of the distal radius fracture, except the volar rim fragments, as they are distal to the buttressing surface. Therefore, we prefer a hook plate extension on a volar locking plate ( - Fig. 7). This construct was inspired by fragment specific fixation which allowed the decision of whether VMF fixation was required to be made following restoration of most of the fracture segments. With the vascular concerns of VMFs, rigidity of the fixation construct is an important predictor for revascularization. ${ }^{36}$ After appropriate reduction and application of the volar plate, the distal fragment can be assessed. If the fracture line is distal to the buttressing capacity of the plate, a hook plate extension is added.

\section{Summary}

The volar rim of the distal radius is the only bony impediment to volar carpal subluxation. Therefore, after distal radius fracture, functional outcomes are dependent on the 
anatomical integrity of the volar rim. Because volar rim fragments may not be apparent on a preoperative radiograph, an extensive intraoperative evaluation of the fracture anatomy should be a component of every surgical intervention. Appropriate management of the VMF comprises two steps-recognition of its presence and rigid anatomical repair. Failure on either of these steps leads to a high likelihood of wrist subluxation and fragment resorption. The best opportunity for a predictable successful result in the presence of a VMF is its adequate initial treatment.

\section{Funding}

None.

\section{Conflict of Interest}

Irrevocable trusts of which J.L.O. and family members are the beneficiaries, own stock in Skeletal Dynamics, and the company reimburses expenses when he speaks or presents on the company's behalf.

\section{References}

1 Lill CA, Goldhahn J, Albrecht A, Eckstein F, Gatzka C, Schneider E. Impact of bone density on distal radius fracture patterns and comparison between five different fracture classifications. J Orthop Trauma 2003;17(04):271-278

2 Mandziak DG, Watts AC, Bain GI. Ligament contribution to patterns of articular fractures of the distal radius. J Hand Surg Am 2011;36(10):1621-1625

3 Melone CP Jr. Distal radius fractures: patterns of articular fragmentation. Orthop Clin North Am 1993;24(02):239-253

4 Smith RS, Crick JC, Alonso J, Horowitz M. Open reduction and internal fixation of volar lip fractures of the distal radius. J Orthop Trauma 1988;2(03):181-187

5 Harness NG, Jupiter JB, Orbay JL, Raskin KB, Fernandez DL. Loss of fixation of the volar lunate facet fragment in fractures of the distal part of the radius. J Bone Joint Surg Am 2004;86(09):1900-1908

6 Lewis OJ, Hamshere RJ, Bucknill TM. The anatomy of the wrist joint. J Anat 1970;106(Pt 3):539-552

7 Apergis E, Darmanis S, Theodoratos G, Maris J. Beware of the ulnopalmar distal radial fragment. J Hand Surg $[\mathrm{Br}]$ 2002;27(02):139-145

8 Andermahr J, Lozano-Calderon S, Trafton T, Crisco JJ, Ring D. The volar extension of the lunate facet of the distal radius: a quantitative anatomic study. J Hand Surg Am 2006;31(06):892-895

9 Mekhail AO, Ebraheim NA, McCreath WA, Jackson WT, Yeasting RA. Anatomic and X-ray film studies of the distal articular surface of the radius. J Hand Surg Am 1996;21(04):567-573

10 Berger RA. The anatomy of the ligaments of the wrist and distal radioulnar joints. Clin Orthop Relat Res 2001;(383):32-40

11 Berger RA, Landsmeer JM. The palmar radiocarpal ligaments: a study of adult and fetal human wrist joints. J Hand Surg Am 1990; 15(06):847-854

12 Orbay J. Volar plate fixation of distal radius fractures. Hand Clin 2005;21(03):347-354

13 Bergsma M, Doornberg JN, Hendrickx L, et al. Interpretations of the term "watershed line" used as reference for volar plating. J Wrist Surg 2020;9(03):268-274

14 Soong M, Earp BE, Bishop G, Leung A, Blazar P. Volar locking plate implant prominence and flexor tendon rupture. J Bone Joint Surg Am 2011;93(04):328-335

15 Selles CA, Reerds STH, Roukema G, van der Vlies KH, Cleffken BI, Schep NWL. Relationship between plate removal and Soong grading following surgery for fractured distal radius. J Hand Surg Eur Vol 2018;43(02):137-141
16 O'Driscoll SW, Horii E, Ness R, Cahalan TD, Richards RR, An KN. The relationship between wrist position, grasp size, and grip strength. J Hand Surg Am 1992;17(01):169-177

17 Genda E, Horii E. Theoretical stress analysis in wrist joint-neutral position and functional position. J Hand Surg [Br] 2000;25(03): 292-295

18 Viegas SF, Tencer AF, Cantrell J, et al. Load transfer characteristics of the wrist. Part I. The normal joint. J Hand Surg Am 1987;12(06): 971-978

19 Gíslason MK, Stansfield B, Bransby-Zachary M, Hems T, Nash DH. Load transfer through the radiocarpal joint and the effects of partial wrist arthrodesis on carpal bone behaviour: a finite element study. J Hand Surg Eur Vol 2012;37(09):871-878

20 Guo X, Fan Y, Li ZM. Effects of dividing the transverse carpal ligament on the mechanical behavior of the carpal bones under axial compressive load: a finite element study. Med Eng Phys 2009;31(02):188-194

21 Tang P, Gauvin J, Muriuki M, Pfaeffle JH, Imbriglia JE, Goitz RJ. Comparison of the "contact biomechanics" of the intact and proximal row carpectomy wrist. J Hand Surg Am 2009;34(04):660-670

22 Pauwels F. Gesammelte Abhandlungen zur Biomechanik des Bewegungsapparates. Berlin Heidelberg, New York: Springer; 1965

23 Giunta R, Löwer N, Wilhelm K, Keirse R, Rock C, Müller-Gerbl M. Altered patterns of subchondral bone mineralization in Kienböck's disease. J Hand Surg [Br] 1997;22(01):16-20

24 Orbay JL, Rubio F, Vernon LL. Prevent collapse and salvage failures of the volar rim of the distal radius. J Wrist Surg 2016;5(01):17-21

25 Majima M, Horii E, Matsuki H, Hirata H, Genda E. Load transmission through the wrist in the extended position. J Hand Surg Am 2008;33(02):182-188

26 Orbay JL, Gray R, Vernon LL, Sandilands SM, Martin AR, Vignolo $\mathrm{SM}$. The EFCR approach and the radial septum-understanding the anatomy and improving volar exposure for distal radius fractures: imagine what you could do with an extra inch. Tech Hand Up Extrem Surg 2016;20(04):155-160

27 Sheetz KK, Bishop AT, Berger RA. The arterial blood supply of the distal radius and ulna and its potential use in vascularized pedicled bone grafts. J Hand Surg Am 1995;20(06):902-914

28 Shin AY, Bishop AT. Vascular anatomy of the distal radius: implications for vascularized bone grafts. Clin Orthop Relat Res 2001;(383):60-73

29 Kachooei AR, Tarabochia M, Jupiter JB. Distal radius volar rim fracture fixation using DePuy-Synthes volar rim plate.J Wrist Surg 2016;5(01):2-8

30 Naito K, Sugiyama Y, Kinoshita M, et al. Functional outcomes in volar-displaced distal radius fractures patients with marginal rim fragment treated by volar distal locking plates. J Hand Microsurg 2019;11(02):100-105

31 O'Shaughnessy MA, Shin AY, Kakar S. Stabilization of volar ulnar rim fractures of the distal radius: current techniques and review of the literature. J Wrist Surg 2016;5(02):113-119

32 Gavaskar AS, Parthasarathy S, Balamurugan J, Raj RV, Anurag R, Gopinath D. Volar hook plate stabilization of volar marginal fragments in intra-articular distal radius fractures. Injury 2021;52(01): $85-89$

33 Chin KR, Jupiter JB. Wire-loop fixation of volar displaced osteochondral fractures of the distal radius. J Hand Surg Am 1999;24 (03):525-533

34 Moore JA Jr, Shank JR, Morgan SJ, Smith WR. Syndesmosis fixation: a comparison of three and four cortices of screw fixation without hardware removal. Foot Ankle Int 2006;27(08):567-572

35 Bakker AJ, Shin AY. Fragment-specific volar hook plate for volar marginal rim fractures. Tech Hand Up Extrem Surg 2014;18(01): $56-60$

36 Lienau J, Schell H, Duda GN, Seebeck P, Muchow S, Bail HJ. Initial vascularization and tissue differentiation are influenced by fixation stability. J Orthop Res 2005;23(03):639-645 